\title{
Ordered Growth of Anodic Aluminum Oxide in Galvanostatic and Galvanostatic-Potentiostatic Modes
}

\section{Mukhurov NI*, Gasenkova IV and Andruhovich IM}

Laboratory of Micro-electronics, Mechanics and Sensorics, B.S. Stepanov Institute of Physics NAS of Belarus, Minsk, Belarus

${ }^{*}$ Corresponding author: Mukhurov NI, Laboratory of Micro-electronics, Mechanics and Sensorics, B.S. Stepanov Institute of Physics NAS of Belarus, Minsk, Belarus, E-mail: n.mukhurov@dragon.bas-net.by

Citation: Mukhurov NI, Gasenkova IV, Andruhovich IM (2014) Ordered Growth of Anodic Aluminum Oxide in Galvanostatic and Galvanostatic-Potentiostatic Mode. J Mater Sci Nanotechnol 1(1): S110.

doi: 10.15744/2348-9812.1.S110

Received Date: May 28, 2014 Accepted Date: May 30, 2014 Published Date: September 05, 2014

\begin{abstract}
The results are presented of obtaining anodic aluminum oxide with an ordered pore arrangement by employing two anodizing modes - galvanostatic mode and combined (galvanostatic + potentiostatic) mode, at high values of the current density and voltage. Use has been made of an oxalate electrolyte and a complex electrolyte comprising oxalic acid and phosphoric acid. Scanning electron microscopy has been used to investigate the surface morphology of the barrier and porous layers and to determine pore sizes and interpore distance. It is shown that annealing of aluminum prior to anodizing in the temperature range from 220 to $450^{\circ} \mathrm{C}$ has no significant effect on the morphology of the surfaces.
\end{abstract}

Keywords: Anodic aluminum oxide; Annealing aluminum; Galvanostatic and Potentiostatic modes; Ordered oxide samples

\section{Introduction}

Anodic aluminum oxide (AAO) has been used for various applications in the fields of optoelectronics, energy storage, separation, sensing, etc. [1-11]. AAO is widely used as a template for producing nanotubes, nanowires, nanorods and nanoparticles [1214]. This creates a high interest of researchers in the study of anodizing process, the mechanisms of growth and conditions of production of ordered oxide as well as in the study of the effect of anodizing parameters, electrolyte temperature on the diameters of pores, inter-pore spacing and pore ordering [15-17].

A number of methods have been proposed in the literature [18-22] for producing porous AAO with a high degree of structural ordering. A two-step method of obtaining ordered structures of anodic aluminum oxide is described in [18]. This method involves growing of the oxide in potentiostatic mode at low voltages, followed by subsequent selective etching of the first layer and formation of the second AAO layer on the surface thus prepared. The process of AAO production at low forming voltages is called "mild" anodizing [19]. This method makes it possible to obtain highly ordered AAO structures but its shortcoming lies in increased duration of the process. Widely known is the method of forming of ordered AAO structures at high voltages that is also called "hard" anodizing [20]. By the latter method highly ordered structures are produced in a much shorter time. It should be noted that carrying out of the anodizing process under hard conditions requires strict temperature control and efficient removal of heat from the anode to avoid overheating and destroying of the integrity of specimens.

Thus, the known methods of forming ordered AAO layers are based on the use of the potentiostatic anodizing mode. The galvanostatic mode mainly employed in industry has almost never been used for producing ordered structures.

In this paper we have considered the possibility of making ordered AAO structures in the galvanostatic and combined modes at high forming voltages and high current densities. While preparing the aluminum plates before anodizing, the influence of annealing temperature of the starting aluminum on the degree of ordering has been studied.

\section{Experimental}

The AAO samples studied were made on aluminum substrates subjected to preliminary preparation process. The aluminum plates were degreased in boiling benzene and isopropyl alcohol. Then, they were dried at $100{ }^{\circ} \mathrm{C}$ for 30 min. To impart planarity and reduce mechanical stress, the aluminum plates were subjected to thermal flattening. They were clamped between the straightening plates whose thermal expansion coefficient was 2.5 times less than that of aluminum and heated to $100{ }^{\circ} \mathrm{C}$ under pressure of 12 $\mathrm{MPa}$. When cooled in the clamped position the plates underwent plastic deformation uniformly in all directions. Annealing was 
performed at $220^{\circ} \mathrm{C}$ in air for $30 \mathrm{~min}$. Next, the aluminum plates were electrochemically polished in a solution of ortho-phosphoric and acetic acids at a temperature of $75-80^{\circ} \mathrm{C}$. Thereafter, aluminum was anodized to the depth of 0.5 microns in a $3 \%$ solution of oxalic acid in the galvanostatic mode with the current density of $15 \mathrm{~mA} / \mathrm{cm}^{2}$ and the electrolyte temperature of $45 \pm 2{ }^{\circ} \mathrm{C}$ and then in the potentiostatic mode with the voltage $40 \mathrm{~V}$ and the electrolyte temperature of $10 \pm 2{ }^{\circ} \mathrm{C}$. The resulting layer was removed in a water solution of ortho-phosphoric acid and chromic acid.

Separation of the resulting oxide from the unanodized aluminum was performed by two methods: by liquid chemical etching of aluminum and by explosion method.

The methods used for oxide formation in the galvanostatic mode were different from each other by the used values $(\mathrm{COOH})_{2}$ of the initial and final densities of the anodizing current. In all cases, the electrolyte temperature was $1^{\circ} \mathrm{C}$ and the current density was raised at a rate of $0.1 \mathrm{~mA} / \mathrm{cm}^{2}$ per 0.5 seconds. When the final value of the current density was reached the oxide growth was continued to the thickness of 15 microns. The AAO specimens were produced in the following ranges in the anodizing current density: 3-80 mA/ $\mathrm{cm}^{2} ; 15-70 \mathrm{~mA} / \mathrm{cm}^{2} ; 20-50 \mathrm{~mA} / \mathrm{cm}^{2}$.

The combined mode consisted in the raising of the current density to a specified level with subsequent switching to the potentiostatic mode wherein the aluminum oxide layer was grown. When a $3 \%$ solution of $(\mathrm{COOH})_{2}$ was used as electrolyte, the current density increased from 30 to $70 \mathrm{~mA} / \mathrm{cm}^{2}$ and the voltage of transition to the potentiostatic mode was $140 \mathrm{~V}$. When using a $3 \%$ solution of $(\mathrm{COOH})_{2}$ and $0.5 \mathrm{M} \mathrm{H}_{3} \mathrm{PO}_{4}$, the current density increased from 20 to $50 \mathrm{~mA} / \mathrm{cm}^{2}$ and the voltage was $150 \mathrm{~V}$.

The surface morphology of the specimens was investigated by scanning electron microscopy (SEM) using the JSM- 5610 LV and CAMSCAN microscopes with EDX analyzer.

\section{Results and Discussions}

The time dependences of the electric current and voltage corresponding to various versions of the galvanostatic mode are shown in Figure 1.

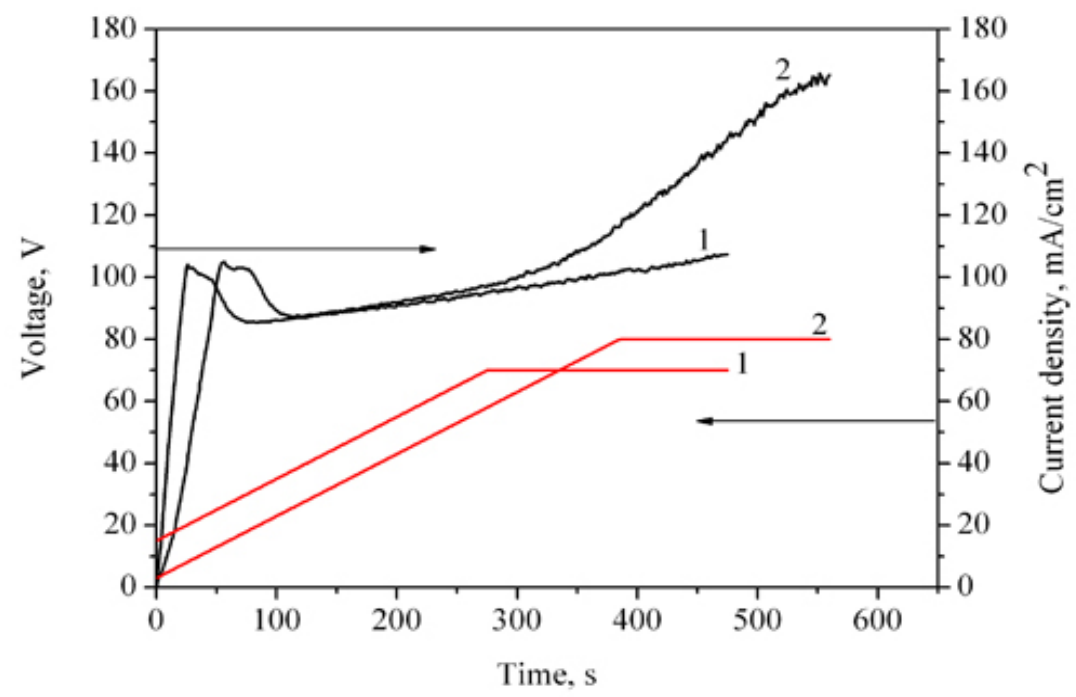

Figure 1: The time dependence of voltage and current density in the anodizing process:

1 - with the current density changing from 30 to $70 \mathrm{~mA} / \mathrm{cm}^{2}, 2$ - with the current density changing from 3 to $80 \mathrm{~mA} / \mathrm{cm}^{2}$.

The SEM images of the electrolyte-oxide and oxide-aluminum interfaces are shown in Figure 2. The SEM images of the electrolyteoxide interfaces for all specimens obtained are typical of the ordered oxide obtained in the potentiostatic modes [19]. An ordered arrangement of pores and their uniform size distribution are observed within the regions investigated. The difference is found in the sizes of pores. However, the ordering is as good as that observed in mild anodization in oxalic acid, or even better [23,24].

On the oxide-aluminum interface side, the surface morphology of the oxide formed at $70 \mathrm{~mA} / \mathrm{cm}^{2}$ is characterized by the highest degree of structural ordering as compared with the oxide formed at $80 \mathrm{~mA} / \mathrm{cm}^{2}$. According to SEM, the size of a separate cell in such specimen is $225 \mathrm{~nm}$ whereas the pore diameter on the oxide-electrolyte interface side is $50 \mathrm{~nm}$. The structure of AAO obtained at $80 \mathrm{~mA} / \mathrm{cm}^{2}$ is low-ordered on the oxide-aluminum interface side. The cell size varies strongly and cells have arbitrary shapes, which is typical of a disordered oxide. This specimen shows the largest size of cell (320 nm) and the pore diameter (70 nm). The comparison of the voltage-vs-time behavior (Figure 1) shows that when the oxide is formed at $80 \mathrm{~mA} / \mathrm{cm}^{2}$ the electric voltage changes significantly in a wide range of about $50 \mathrm{~V}$, whereas at $70 \mathrm{~mA} / \mathrm{cm}^{2}$ the voltage changes by no more than $20 \mathrm{~V}$, which creates the conditions for the growth of periodic homogeneous cells. Thus, if the galvanostatic mode ensures a gradual increase in the voltage, the formation of ordered alumina becomes possible. 


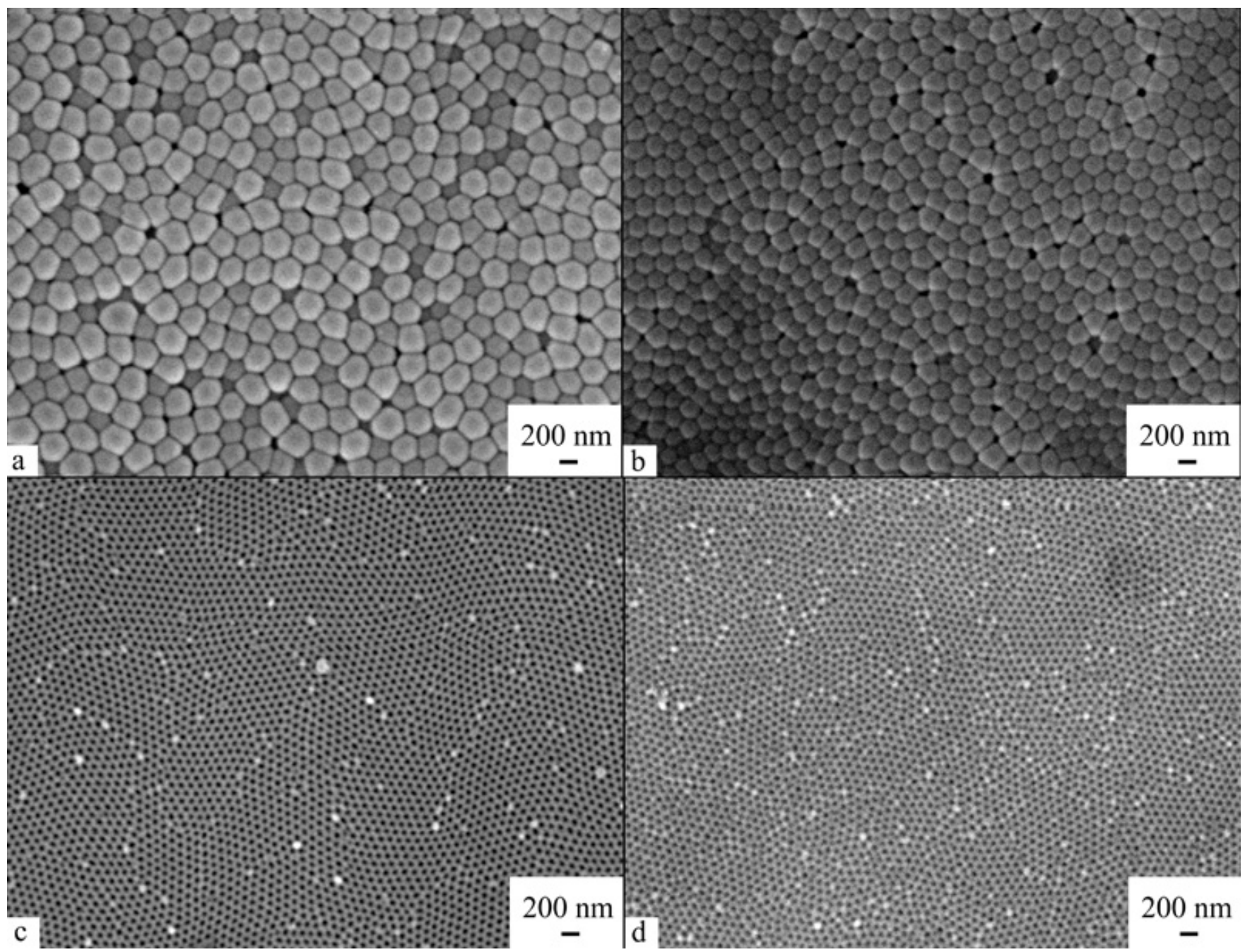

Figure 2: The SEM images of the AAO interfaces viewed from the porous layer side (a, b) and from the barrier layer side (c, d) obtained in $3 \%(\mathrm{COOH}){ }_{2}$ in the galvanostatic mode at intervals (ranges) of the current density of $15-70 \mathrm{~mA} / \mathrm{cm}^{2}\left(\mathrm{a}, \mathrm{c}\right.$ ) and $3-80 \mathrm{~mA} / \mathrm{cm}^{2}(\mathrm{~b}, \mathrm{~d})$.

The potentiostatic anodizing mode at high voltage values involves either the pre-growth of a buffer oxide layer at low voltages or the growth of the layer by gradually increasing voltage from zero to the required level $[19,20,24]$. In both cases, the morphological parameters of the oxide layer will be different from the parameters obtained in the main mode. A number of practical applications require that the morphological parameters should be invariable. Formation of the oxide in the galvanostatic mode at the initial stage of growth was chosen to reduce thickness of the buffer layer and to minimize parameter difference. According to [25,26], at the first stage of growth a barrier layer is formed that prevents breakdown. At the pore formation stage, a major rise in the current density occurs, whereas the oxide growth takes place at a constant electric current. Then, it is possible to switch to the potentiostatic mode taking into account the required size of cells which is determined by the final value of the voltage. Figures 3,4 show the time dependences and morphologies of the specimens produced in the mode described. The specimens have the following dimensional features: pore size $\sim 80 \mathrm{~nm}$ and inter-pore distance $\sim 360 \mathrm{~nm}$. We have also obtained better arrangement of pores than in [27]. A more detailed determination of the factors affecting the formation of an ordered anodic oxide in the galvanostatic mode in various electrolytes and current densities will be the subject of our future research.

As known, ordered growth of AAO involves annealing at high temperatures that ensures recrystallization and relieving of both surface and internal mechanical stresses $[20,28,29]$. Without changing the conditions of preparation of aluminum, we have studied the effect of aluminum annealing temperature on the degree of ordering. Aluminum was annealed at 400,450 and $500{ }^{\circ} \mathrm{C}$ with the annealing time of 30 minutes. The results were compared with those obtained without annealing. Specimens were anodized using the two-step procedure [18]. Figure 5 shows the surface morphologies. No significant difference in the morphology of the surfaces is observed at 400 and $450{ }^{\circ} \mathrm{C}$ and without annealing. Images of the specimens after annealing at 220 and $400{ }^{\circ} \mathrm{C}$ are not presented in as much as they are qualitatively similar to the images taken from the specimens annealed at $450^{\circ} \mathrm{C}$. The AAO surface morphology markedly changes only after annealing at $500{ }^{\circ} \mathrm{C}$, with the degree of disorder being higher. In addition, characteristic defects are observed caused by defects arising on aluminum after electropolishing (Figure 5). Perhaps, the electropolishing regime should be changed as it affects the degree of ordering. Based on the results, conclusion can be made that this kind of preparation of aluminum makes it possible to produce ordered AAO structures without annealing at high temperatures or with annealing at temperatures less than $450^{\circ} \mathrm{C}$ and annealing time of no more than 30 minutes. 


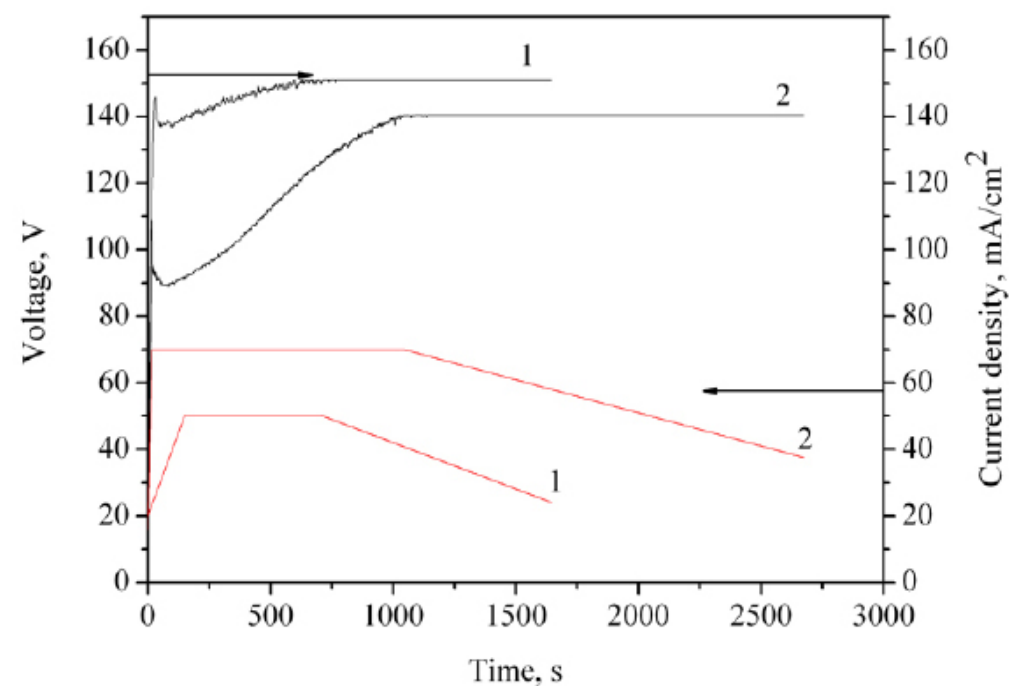

Figure 3: Time dependence of the voltage and current density in the combined mode $1-3 \%(\mathrm{COOH})_{2} ; 2-3 \%(\mathrm{COOH})_{2}$ and $0,5 \mathrm{M} \mathrm{H}_{3} \mathrm{PO}_{4}$.

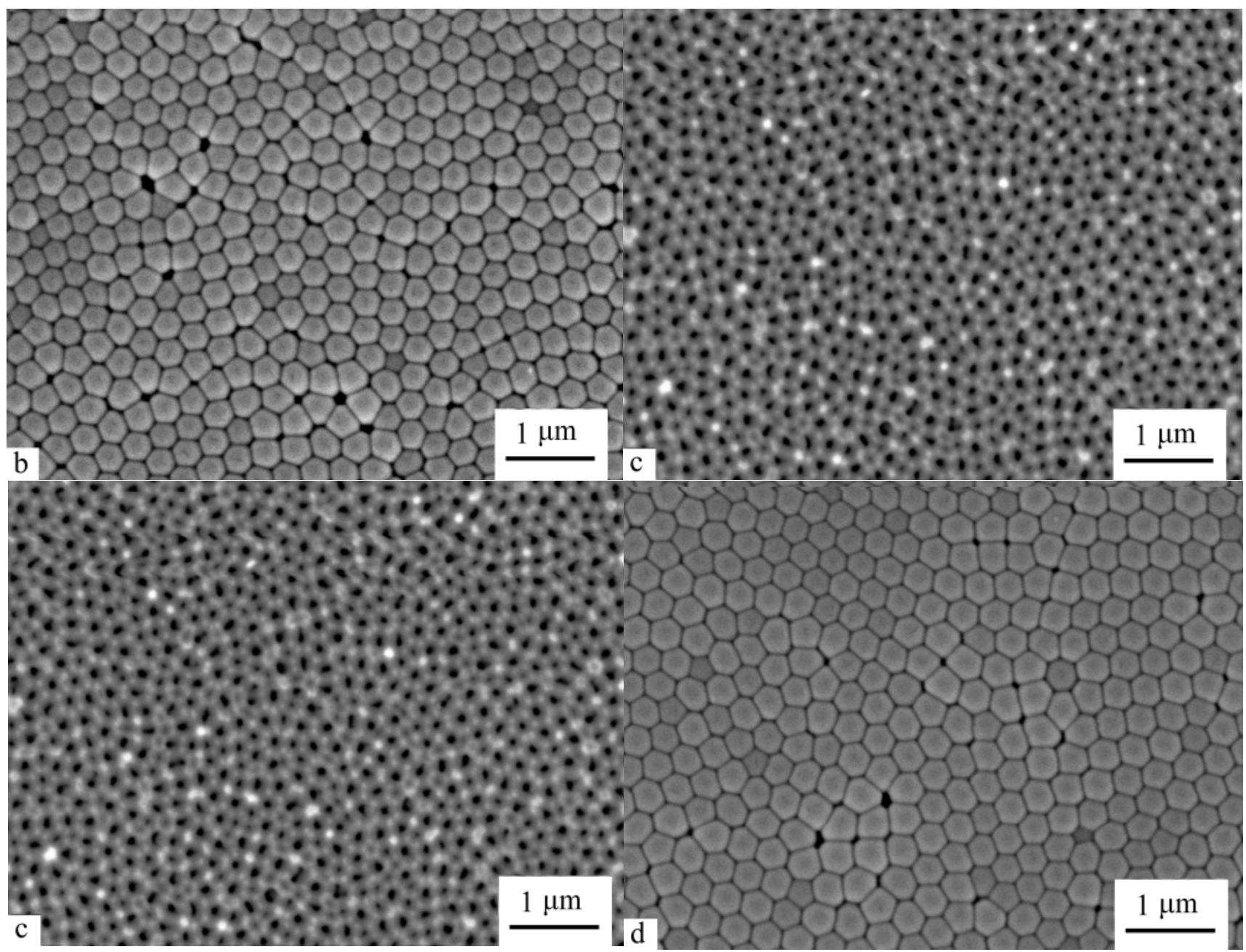

Figure 4: SEM image of the AAO surface morphology viewed from the porous layer side (a, c) and from the barrier layer side (b, d) obtained in $3 \%(\mathrm{COOH})_{2}$ $(\mathrm{a}, \mathrm{b})$ and $3 \%(\mathrm{COOH})_{2}$ and $0.5 \mathrm{M} \mathrm{H}_{3} \mathrm{PO}_{4}(\mathrm{c}, \mathrm{d})$. 


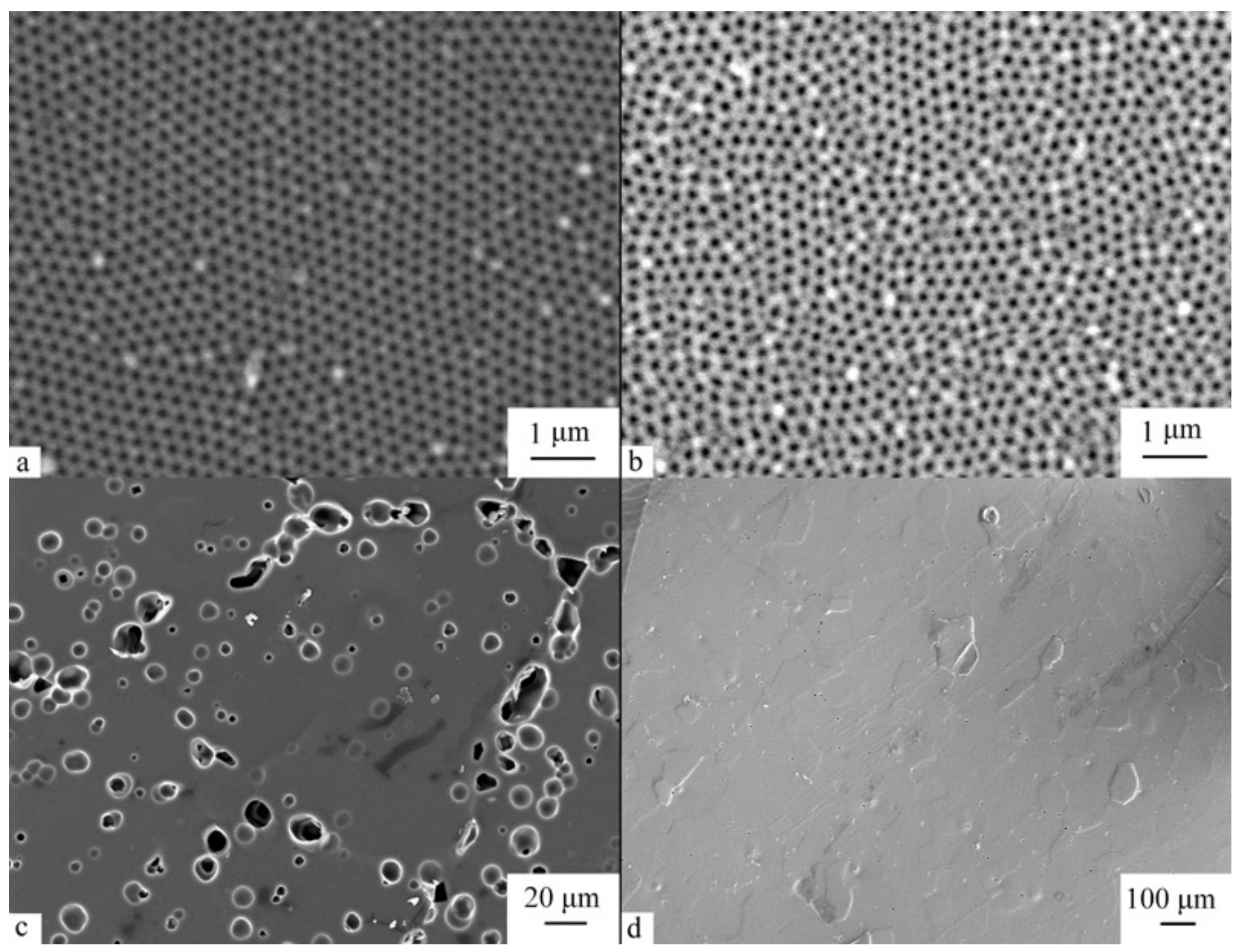

Figure 5: AFM (a) and SEM images of AAO formed on aluminum annealed at $450{ }^{\circ} \mathrm{C}$ (a) and at $500{ }^{\circ} \mathrm{C}(\mathrm{b}, \mathrm{c})$. SEM image of aluminum annealed at $500^{\circ} \mathrm{C}(\mathrm{d})$.

The increasing of grain size in the starting aluminum during annealing (Figure 5) does not lead to increase of the size of regions with a high degree of pore ordering, which is consistent with the findings given in [29]. The effect caused by the starting aluminum is limited by the extent of purity and quality of the substrate. The results obtained are in good agreement with the observations made in [30] where the ordered oxide growth is limited only by the parameters of chemical and electrochemical polishing of aluminum. The results of our study suggest that the described method of aluminum preparation can be used as alternative one.

\section{Conclusion}

The possibility has been demonstrated of forming anodic aluminum oxide with an ordered pore arrangement by employing the galvanostatic anodizing mode and a combination of the galvanostatic and potentiostatic modes, which allows the use of such methods in industrial applications. It is worth noting that the specimens were produced without cooling of the aluminum plate. The influence has been studied of the aluminum annealing at temperatures ranging from 220 to $500{ }^{\circ} \mathrm{C}$ on the degree of ordering of the final anodic aluminum oxide samples. According to SEM data, no significant differences are observed in the surface morphologies of anodic aluminum oxide produced on the aluminum annealed up to $450{ }^{\circ} \mathrm{C}$. The AAO formed on the aluminum annealed at $500{ }^{\circ} \mathrm{C}$ is characterized by smaller regions of cell ordering as compared to the oxide formed on aluminum annealed at lower temperatures. It should be mentioned that the films have macroscopic defects that have not been observed in any other process conditions.

\section{References}

1. Mutalib JA, Losic D, Voelcker NH (2013) Nanoporous anodic aluminium oxide: Advances in surface engineering and emerging applications. Progress in Materials Science 58: 636-704.

2. Wang J, Li Y, Wang D-S, Wang C-W (2012) The optical responses of one-dimensional photonic crystals based on the transparent Ag-anodic aluminum oxide composites with super low-refractive index. Thin Solid Films 520: 6970-4. 
3. Kolar J, Macak JM, Terabe K, Wagner T (2014) Down-scaling of resistive switching to nanoscale using porous anodic alumina membranes. J Mater Chem 2: 349-55.

4. Mardilovich PP, Govyadinov AN, Mukhurov NI, Rzhevski AR, Paterson R (1995) New and modified anodic alumina membrans: Part.I. Thermotreatment of anodic alumina membranes. J of Membrane Science 98: 131-42.

5. Osmanbeyoglu HU, Hur TB, Kim HK (2009) Thin alumina nanoporous membranes for similar size biomolecule separation. Journal of Membrane Science 343: $1-6$.

6. Gasenkova IV, Mukhurov NI, Zhvavyi SP (2012) Photoluminescence properties of anodic alumina. Physics Research and Technology, Nova Science Publishers, 400 Oser Avenue, Suite 1600: 195-225.

7. Li T, Li L, Zhang G (2014) A Nano-scaled force sensor based on a photonic crystal nanocavity resonator and a microcantilever. ECS J Solid State Sci Technol 3: Q146-51.

8. Yan P, Fei GT, Shang GL, Wu B, Zhang LD (2013) Fabrication of one-dimensional alumina photonic crystals with a narrow band gap and their application to high-sensitivity sensors. J Mater Chem 1: 1659-64.

9. Grigorishin IL, Kotova IF, Mukhurov NI (1997) Design and technological peculiarities of making vacuum integrated circuits of a thermocathode-based AC amplifier. Applied Surface Science 111: 101-5.

10. Tsao YC, Søndergaard T, Skovsen E, Gurevich L, Pedersen K, et al. (2013) Pore size dependence of diffuse light scattering from anodized aluminum solar cell backside reflectors. Opt Express 21: A84-95.

11. Santos A, Kumeria T, Losic D (2014) Nanoporous anodic alumina: A versatile platform for optical biosensors. Materials 7: 4297-320.

12. Zhang Z, Zhang JJ, Hou X, Wu TS, Sun HY (2014) Iridescent thin films of porous anodic aluminum oxide with embedded silver nanowires. Thin Solid Films 558: 344-8.

13. Zhang J, Kielbasa JE, Carroll DL (2010) Controllable fabrication of porous alumina templates for nanostructures synthesis. Materials Chemistry and Physics 122: $295-300$.

14. Mondal B, Saha SK (2010) Fabrication of SERS substrate using nanoporous anodic alumina template decorated by silver nanoparticles. Chemical Physics Letters 497: 89-93.

15. Ali G, Ahmad M, Akhter JI, Maqbool M, Cho SO (2010) Novel structure formation at the bottom surface of porous anodic alumina fabricated by single step anodization process. Micron 41: 560-4.

16. Manzano CV, Martin J, Martin-Gonzalez MS (2014) Ultra-narrow $12 \mathrm{~nm}$ pore diameter self-ordered anodic alumina templates. Microporous and Mesoporous Materials 184: 177-83.

17. Curioni M, Koroleva EV, Skeldon P, Thompson GE (2010) Flow modulated ionic migration during porous oxide growth on aluminium. Electrochimica Acta 55: 7044-9.

18. Masuda H, Fukuda K (1995) Ordered metal nanohole arrays made by a two-step replication of honeycomb structures of anodic alumina. Science 268: $1466-8$. 19. Kashi MA, Ramazani A, Raoufi M, Karimzadeh A (2010) Self-ordering of anodic nanoporous alumina fabricated by accelerated mild anodization method. Thin Solid Films 518: 6767-72.

20. Lee W, Ji R, Gosele U, Nielsch K (2006) Fast fabrication of long-range ordered porous alumina membranes by hard anodization. Nature Materials 5: 741-7. 21. Jaafar M, Navas D, Hernandes-Velez M, Baldonedo JL, Vazquez M, et al. (2009) Nanoporous alumina membrane prepared by nanoindentation and anodic oxidation. Surface Science 603: 3155-9.

22. Liu J, Liu S, Zhoua H, Xie C, Huang Z, et al. (2014) Preparation of self-ordered nanoporous anodic aluminum oxide membranes by combination of hard anodization and mild anodization. Thin Solid Films 552: 75-81.

23. Stepniowski WJ, Zasada D, Bojar Z (2011) First step of anodization influences the final nanopore arrangement in anodized alumina. Surface and Coatings Technology 206: 1416-22.

24. Zaraska L, Stepniowski WJ, Jaskula M, Sulka GD (2014) Analysis of nanopore arrangement of porous alumina layers formed by anodizing in oxalic acid at relatively high temperatures. Applied Surface Science 305: 650-7.

25. Parkhutik VP, Shersulsky VI (1992) Theoretical modelling of porous oxide growth on aluminium. J. Phys. D.: Appl. Phys. 25: 1258-63.

26. Wood GC, O'Sullivan JP (1970) The anodizing of Aluminium in Sulphate Solutions. Electrochemical Acta 15: 1865-76.

27. Zaraska L, Sulka GD, Jaskula M (2010) The effect of n-alcohols on porous anodic alumina formed by self-organized two-step anodizing of aluminum in phosphoric acid. Surface and Coatings Technology 204: 1729-37.

28. Jessensky O, Müller F, Gösele U (1998) Self-Organized Formation of Hexagonal Pore Structures in Anodic Alumina. J Electrochem Soc 145: 3735-40.

29. Beck G, Petrikowski K (2008) Influence of the microstructure of the aluminium substrate on the regularity of the nanopore arrangement in an alumina layer formed by anodic oxidation. Surface and Coatings Technology 202: 5084-91.

30. Alam KM, Singh AP, Bodepudi SC, Pramanik S (2011) Fabrication of hexagonally ordered nanopores in anodic alumina: An alternative pretreatment. Surface Science 605: 441-9.

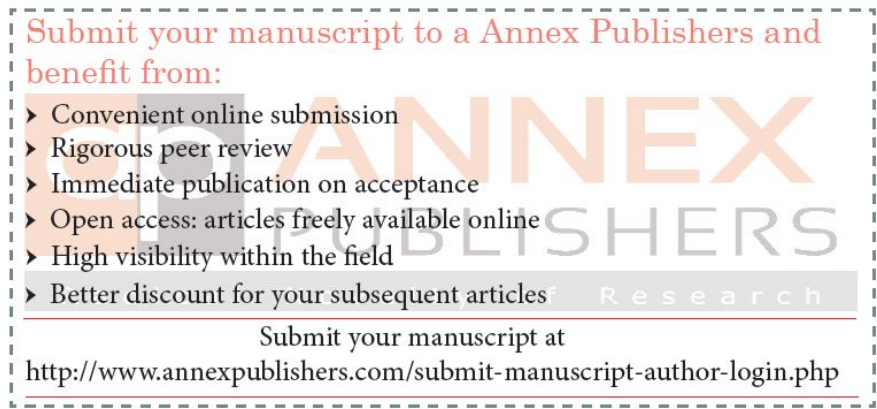

